\title{
anatomy
}

\section{Invitation from the Congress President of the 21st National Anatomy Congress}

Anatomy 2020;14(Suppl 1):Siv @2020 Turkish Society of Anatomy and Clinical Anatomy (TSACA)

Dear Colleagues,

I would like to start by offering my sincerest greetings to all anatomists in the World and in Turkey. Even though the pandemia has created a lot of negativity, I am so proud to invite you all to the 21st National Anatomy Congress. Meaning that, I remember with respect everyone including health care professionals who have passed away due to covid 19 .

This is the first time that an anatomy congress is being organized online. Even though, I believe that the congress will be a success with your interest and participation. The Board members of TSACA have managed to finalize all preparations for the congress in a short period of time. Hereby, we would like to thank everyone who has supported us by organizing precourses, and accepting our invitation to be a speaker and to be part of panel discussions. This way we have organized sessions to discuss translational anatomical researches, place of anatomical studies in clinical researches and problems of online education as well as problems of anatomy education before and after graduation.

Thanks to the infrastructure of Ankara University, we will be able to organize more discussions and speeches in three dif- ferent online meetings with parallel sessions. We will provide a speech opportunity to the congress members also for poster presentations. Hereby we would like to thank the Rectorate of Ankara University for this opportunity.

Beside advantages of online organization, there are disadvantages as well. Due to the actual situation, we could not organize any social program. We will try to compensate for this by providing more discussion and speaking opportunities during sessions. Because of this all participants will be able to turn on both cameras and microphones as well during sessions. The Congress organization committee as The Board Members of TSACA are happy and excited to see all of you even though it is going to be an online event. We still encourage and invite everyone to join us in The 21st National Anatomy Congress.

Hoping to get back to normal so that we can have congresses face to face as soon as possible.

Best Regards,

Esat Adıgüzel

President of TSACA 